\title{
Oxygen Permeability Coefficient of High Density Polyethylene/Cu Nanofibers Nanocomposites below Percolation
}

\author{
Atheer Mohammad Almasri * \\ ${ }^{a}$ Department of Chemical Engineering, College of Engineering, Al Imam Mohammad Ibn Saud Islamic \\ University - IMSIU, Kingdom of Saudi Arabia
}

Received: August 10, 2015; Revised: August 29, 2015

\begin{abstract}
The main objective of this study was to relate the elastic modulus of a polymer nanocomposite to its permeability coefficient. The materials studied included high density polyethylene (HDPE) filled with copper nanofibers (Cu-nanofibers). Both of the experimental values of the elastic modulus and the gas permeability coefficient of the HDPE/Cu-nanofibers films were obtained from Grigoriadou et al. and Bikiaris \& Triantafyllidis studies. In this study, the Halpin-Tsai model was modified and then used to fit the elastic modulus experimental data. It was found that the modified shape factor $\left(\omega^{\prime}\right)$ of the $\mathrm{Cu}$ fibers as a function of the composite volume fraction is $125 \exp (-41 \varnothing)$. Then, the model was used to predict the oxygen permeability coefficient of the HDPE/Cu-nanofibers films below the percolation point. It was found that the tensile modulus of the nanocomposites increased by $24 \%$ whereas the permeability to oxygen coefficients decreased by $65 \%$ compared to pristine HDPE. Also, the results from the models match the experimental data.
\end{abstract}

Keywords: Cu-nanofiber, polyethylene, Halpin-Tsai model, permeability coefficient, percolation

\section{Introduction}

In the past few decades, polymers have replaced many conventional materials in different applications due to the cost and manufacturability advantages. Polyethylene (PE), for example, is one of the most important, most popular, and cheapest polymers, hence PE is produced in large quantities and is used in many different applications, in particular food packaging wrapping films, pipes, bottles, etc. ${ }^{1}$. PE is widely used because of the many attractive properties such as low density, low cost, low toxicity, and high processability². According to ASTM standards, PE can be low density polyethylene (LDPE), medium density polyethylene (MDPE), or high density polyethylene (HDPE) ${ }^{3}$. PE density range allows a wide range of mechanical and processing behavior; molecular weight, branching, and degree of crystallinity also influence how the PE behaves ${ }^{4}$.

Polymer nanocomposites can be produced by adding fillers. Fillers can be natural fibers such as hemp, rice-husk, textile, chitosan, curauá etc. or inorganic fibers made from materials such as clay, alumina, glass, boron, silicon carbide, carbon etc. It was found that mechanical properties of polymer composites can be enhanced with increasing nanofiller content-as documented in literature ${ }^{5-16}$. It was also found that barrier to gas properties of the polymer composites can be enhanced (i.e. the values of the permeability to gas coefficient reduce as percentage of fiber contents increases) as documented in the literature ${ }^{17-27}$. One important key factor that enhances mechanical properties of the polymer is the aspect ratio of the fillers (i.e. the ratio between the length of the fiber to its diameter). It was found that as the aspect ratio increases, less percentage of the filler is needed.

*e-mail: ammasri@imamu.edu.sa
Thus, better mechanical properties with few amounts of fillers. For example, improvements in mechanical properties have been observed by adding the weight percentages of carbon nanotubes $(\mathrm{CNT})^{28}$. In addition, permeability to gas coefficient is improved by dispersing nanofillers. For instance, reductions in permeability coefficient have been detected by increasing the weight percentages of clay ${ }^{29}$.

This study considers the experimental data from Grigoriadou et al. ${ }^{30}$ on mechanical properties of $\mathrm{HDPE} / \mathrm{Cu}$ nanofiber nanocomposite films and the experimental data from Bikiaris \& Triantafyllidis ${ }^{31}$ on oxygen barrier properties of $\mathrm{HDPE} / \mathrm{Cu}$ nanofiber nanocomposite films. The tensile modulus of elasticity (elastic modulus) and the barrier to oxygen permeability were measured as a function of filler content. The studies are based on the percolation theory ${ }^{32}$ that the materials properties show either a small increase or decrease below the percolation concentration of the filler ${ }^{33}$. When percolation concentration is above threshold, the material properties show a power law increase with filler content $^{34,35}$.

The main objective of this study was to correlate the permeability to oxygen coefficient decrease for HDPE/Cu-nanofiber composite to the mechanical increase of the modulus of elasticity based on a model developed using Halpin-Tsai equation below the percolation point. In addition to the correlation between the permeability and modulus of elasticity of $\mathrm{HDPE} / \mathrm{Cu}$ nanocomposite, it is worthy to study the effect of copper nanofibers when added to PE matrix. For example, $\mathrm{Cu}$ nanofibers are attractive as copper is 100 times cheaper than silver and 1000 times more abundant relative to the other metallic nanofibers ${ }^{36}$. 


\section{Experimental}

This study is based on the elastic modulus experiment findings of the HDPE/Cu-nanofibers films and used as obtained by Grigoriadou et al.$^{30}$, also this study is based on the oxygen permeability coefficients data of the HDPE/Cu-nanofibers films obtained by Bikiaris \& Triantafyllidis ${ }^{31}$. Some modifications were made and will be explained in the Results and Discussion section. . Thus, all materials and samples preparations were taken from the above two references ${ }^{30,31}$.

\subsection{Materials}

High density polyethylene (HDPE) was supplied by Total Petrochemicals (Feluy, Belgium) under the trade name Lumicene mPE M5510 EP. It has a melt flow rate (MFR) of $0.28 \mathrm{~g} / 10 \mathrm{~min}$ at $2.19 \mathrm{~kg} / 190^{\circ} \mathrm{C}$ and density $0.955 \mathrm{~g} / \mathrm{cm}^{3}$ and $\mathrm{T}_{\mathrm{m}} 133^{\circ} \mathrm{C}$. Copper nanofibers were synthesized via the reduction of a copper-amine complex in an aqueous-non polar bilayer system consisted of $\mathrm{CTAB} / \mathrm{TMEDA} / \mathrm{H}_{2} \mathrm{O} / \mathrm{Cyclohexane}$ (for more details look at Cho \& $\mathrm{Huh}^{37}$ ).

\subsection{Nanocomposites preparation}

In Grigoriadou et al. ${ }^{30}$ study; HDPE nanocomposites containing $0.5,1$ and $2.5 \mathrm{wt} \%$ of Cu-nanofibers were prepared by melt mixing in a Haake-Buchler Reomixer (model 600) at $220{ }^{\circ} \mathrm{C}$ and $30 \mathrm{rpm}$ for $15 \mathrm{~min}$ with roller blades and a mixing head with a volumetric capacity of $69 \mathrm{~cm}^{3}$.

\subsection{Mechanical properties}

Measurements of tensile mechanical properties of the prepared nanocomposites in Grigoriadou et al. ${ }^{30}$ study were performed on an Instron 3344 dynamometer, in accordance with ASTM D638 ${ }^{[38]}$, using a crosshead speed of $50 \mathrm{~mm} / \mathrm{min}$. Thin films $(100 \pm 25 \mu \mathrm{m})$ prepared by a PW 30 hydraulic press at a temperature of $220 \pm 3{ }^{\circ} \mathrm{C}$. The thin films were prepared in order to measure the mechanical properties of these sheets, dumb-bell-shaped tensile test specimens (central portions $5 \times 0.5 \mathrm{~mm}$ thick, $22 \mathrm{~mm}$ gauge length) were cut in a Wallace cutting press. Then, the values of Young's modulus were determined.

\subsection{Oxygen permeability}

Oxygen permeability was studied based on Bikiaris and Triantafyllidis ${ }^{31}$ study on relatively thin films $(50 \pm 5 \mu \mathrm{m})$ of HDPE/Cu-nanofiber samples also prepared by a PW 30 hydraulic press at a temperature of $220 \pm 3{ }^{\circ} \mathrm{C}$. Permeability rates of $\mathrm{O}_{2}$ through these films were measured using a Davenport Apparatus (London).

\section{Results and Discussion}

This study is based on the experimental findings of Grigoriadou et al. ${ }^{30}$ and Bikiaris \& Triantafyllidis ${ }^{31}$ for the elastic modulus and oxygen permeability coefficients of the HDPE/Cu-nanofibers films. Grigoriadou et al. ${ }^{30}$ in their HDPE/copper nanofiber nanocomposites study measured the tensile modulus of elasticity (elastic modulus) in accordance with ASTM D $638^{[38]}$ using a crosshead speed of $50 \mathrm{~mm} / \mathrm{min}$. The values of the elastic modulus for plain HDPE is 652 $\mathrm{MPa}$, increased to 735,770 and 805 , when $0.5 \mathrm{wt} \% \mathrm{Cu}$ nanofibers, $1.0 \mathrm{wt} \% \mathrm{Cu}$ nanofiber, and $2.5 \mathrm{wt} \% \mathrm{Cu}$ nanofiber were added, respectively.

In this study, among all of the models used to predict the elastic modulus of composite materials, the Halpin-Tsai model ${ }^{39,40}$ was used to fit the experimental data.

$E_{c}=\frac{1+\omega \frac{\left(E_{f} / E_{m}\right)-1}{\left(E_{f} / E_{m}\right)+\omega} \varnothing}{1-\frac{\left(E_{f} / E_{m}\right)-1}{\left(E_{f} / E_{m}\right)+\omega} \varnothing} E_{m}$

Where $E_{C}, E_{F}$, and $E_{M}$ are the moduli of composite, fiber, and matrix, respectively, $(\omega)$ is the shape factor, and $\varnothing$ is the volume fraction of the filler. The shape factor $(\omega)$ is related to the aspect ratio of reinforcement length $(l)$ and diameter $(d)$ and defined as $(2 l / d)$. Cu-nanofibers used in this study have an average diameter between 200 and $400 \mathrm{~nm}$ and length in the range of 15 to $25 \mu \mathrm{m}$. Thus, the calculated shape factor $(\omega)$ based on the aforementioned data lies between 125 and 150 . The filler volume fraction $(\varnothing)$ is a function of the $\mathrm{Cu}$-nanofibers weight fraction and the densities of both the filler and the matrix as follows

$$
\varnothing=\frac{\frac{w_{f}}{\rho_{f}}}{\frac{w_{f}}{\rho_{f}}+\frac{\left(1-w_{f}\right)}{\rho_{m}}}
$$

Where $w_{F}, w_{M}, \rho_{F}$ and $\rho_{M}$ are Cu-nanofibers weight fraction, matrix weight fraction, $\mathrm{Cu}$-nanofibers density, and matrix density, respectively.

Halpin-Tsai equation was originally used for composites with unidirectional reinforcement, but $\mathrm{Cox}^{41}$ modified and improved it to account for the randomness of discontinuous fibers by introducing an orientation factor $(\beta)^{42}$. If the fiber length is greater than the thickness of specimen, the fibers are assumed to be randomly oriented in two dimensions; and the orientation factor $(\beta)$ is $1 / 3$, while if the fiber length is smaller than the thickness of the specimen, the fibers are assumed to be randomly oriented in three dimensions; and the orientation factor $(\beta)$ is $1 / 6$. In this study, the length range of $\mathrm{Cu}$-nanofibers is shorter than the specimen thickness, $100 \mu \mathrm{m}$, thus $\beta$ is considered to be $1 / 6$ and the Halpin-Tsai equation can be modified to become:

$$
E_{c}=\frac{1+\omega \frac{\beta\left(E_{f} / E_{m}\right)-1}{\beta\left(E_{f} / E_{m}\right)+\omega} \varnothing}{1-\frac{\beta\left(E_{f} / E_{m}\right)-1}{\beta\left(E_{f} / E_{m}\right)+\omega} \varnothing} E_{m}
$$

Moreover, the effective elastic modulus of Cu-nanofibers can be deduced from Equation 2 as follows:

$$
E_{f}=\frac{(\omega+\varnothing) E_{c}-\omega(1-\varnothing) E_{m}}{\beta\left[(\omega \varnothing+1) E_{m}-(1-\varnothing) E_{c}\right]} E_{m}
$$

Linear fitting for $\mathrm{Cu}$-nanofibers/HDPE composites shows an effective elastic modulus of $18 \mathrm{GPa}$. Figure 1 shows the experimental elastic modulus along with the fitted elastic modulus from Halpin-Tsai model (Equation 1) and for the 
modified Halpin-Tsai model (Equation 3). The shape factor $(\omega)$ was 125 for both equations, as a function of $\mathrm{Cu}$-nanofibers.

It is very important to investigate the influence of the shape factor $(\omega)$ on the elastic modulus of the composite $\left(E_{C}\right)$ to account for the randomness of discontinuous $\mathrm{Cu}$ nanofibers. The effect of the shape factor $(\omega)$ on the model curve for elastic modulus of HDPE/Cu composites is shown in Figure 2. Accordingly, the shape factor $(\omega)$ values were taken to be between the minimum of 125 and 150 .

It is evident from Figure 2 that the experimental data need further modification to fit the nonlinear region for the $\mathrm{Cu}$-nanofibers content over $1 \mathrm{wt} \%$. Yeh et al. ${ }^{43}$ have modified the exponential shape factor $(\omega)$ to have the following form

$\omega^{\prime}=\omega e^{-a \varnothing-b}$

Where $\left(\omega^{\prime}\right)$. is the modified shape factor, $(\omega)$ is the shape factor, $a$ and $b$ are constants related to the degree of fillers clusters and agglomerations, which are responsible for the

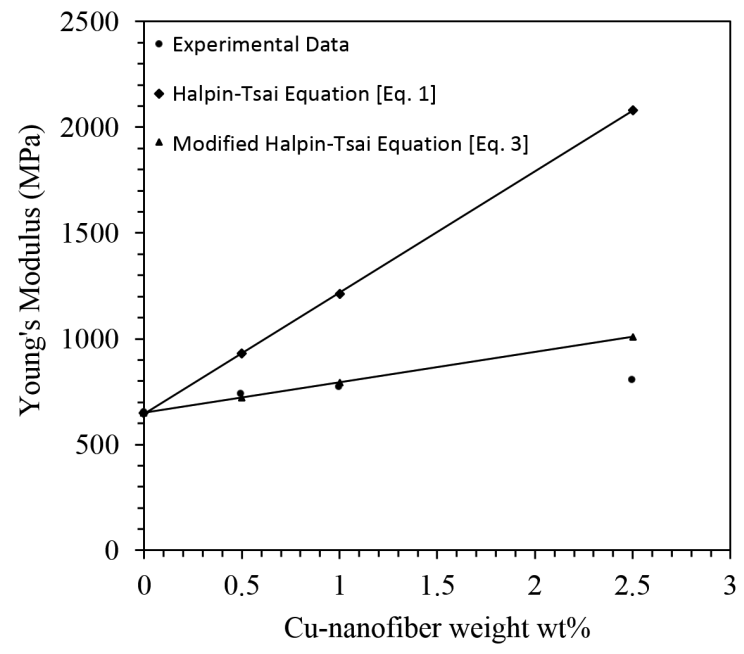

Figure 1. Experimental elastic modulus along with elastic modulus fitted by Halpin-Tsai equation (Equation 1) and the modified HalpinTsai equation (Equation 3).

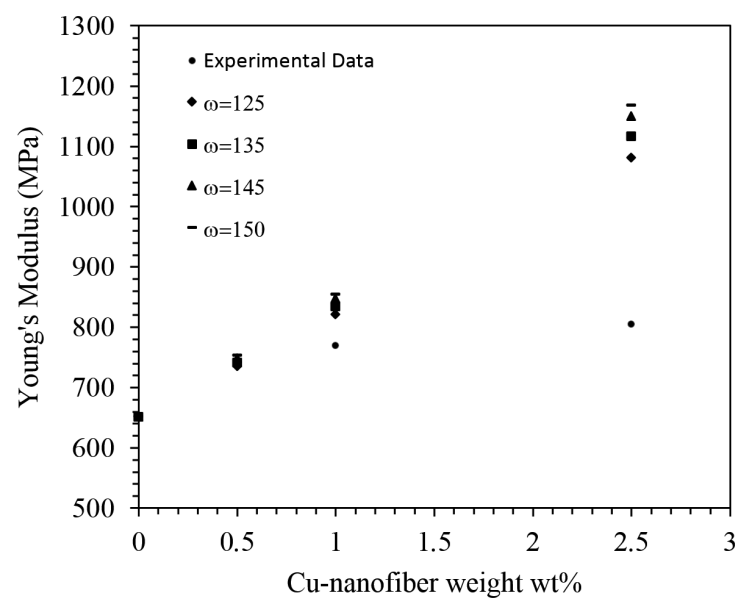

Figure 2. Experimental elastic modulus along with the effect of the shape factor $(\omega)$ on elastic modulus. nonlinear behavior of the Halpin-Tsai equation. Therefore, the larger $a$ nd $b$ values indicate more aggregation of the $\mathrm{Cu}$-nanofiber in the polymeric matrix. Hce, this aggregation of the $\mathrm{Cu}$-nanofibers leads to reduction of the elastic modulus of the composites. Therefore, the modified Halpin-Tsai (Equation 3) can be further modified to become

$$
E_{c}=\frac{1+\omega^{\prime} \frac{\beta\left(E_{f} / E_{m}\right)-1}{\beta\left(E_{f} / E_{m}\right)+\omega^{\prime}} \varnothing}{1-\frac{\beta\left(E_{f} / E_{m}\right)-1}{\beta\left(E_{f} / E_{m}\right)+\omega^{\prime}} \varnothing} E_{m}
$$

Equation 6 is the nonlinear form of the Halpin-Tsai equation, so it fits the $\mathrm{Cu}$-nanofibers over $1 \mathrm{wt} \%$ better. As indicated in Figure 3, large $a$ value tends to reduce the stiffness (Elastic Modulus) of the composite at high $\mathrm{Cu}$-nanofiber loadings. After systematic variation of $a$ in the modified shape factor $\left(\omega^{\prime}\right)$, the results in Figure 3 show that the best value of $a$ to fit the model is 41 with a minimum percentage error between the fit and the experimental Elastic modulus. Also, Figure 3 shows that there is no need to find a fit value of $b$ in the modified shape factor $\omega^{\prime}$, thus $b$ value equals zero.

Both, the small value of $a$ and the zero value of $b$ indicate a little to no aggregations of the $\mathrm{Cu}$-nanofiber in the HDPE matrix. The experiment showed ${ }^{30}$ that no aggregates formed in any $\mathrm{Cu}$-nanofiber content using different characterization techniques, even at high fiber content. This discovery was an advantage because most fillers aggregate and difficult to disperse such as carbon nanotubes.

However, the final form of the Halpin-Tsai model that fits the relative elastic modulus of our experimental data is given by Equation 7 .

$$
\frac{E_{c}}{E_{m}}=\left[\frac{\left.1+125 \exp (-41 \varnothing)\left(\frac{1 / 6\left(E_{f} / E_{m}\right)-1}{1 / 6\left(E_{f} / E_{m}\right)+125 \exp (-41 \varnothing)}\right) \varnothing\right]}{1-\left(\frac{1 / 6\left(E_{f} / E_{m}\right)-1}{1 / 6\left(E_{f} / E_{m}\right)+125 \exp (-41 \varnothing)}\right) \varnothing}\right]
$$

The experimental results in Grigoriadou study ${ }^{30}$ show no significant increase in elastic modulus in line with the percolation theory. The increase was up to $24 \%$ between

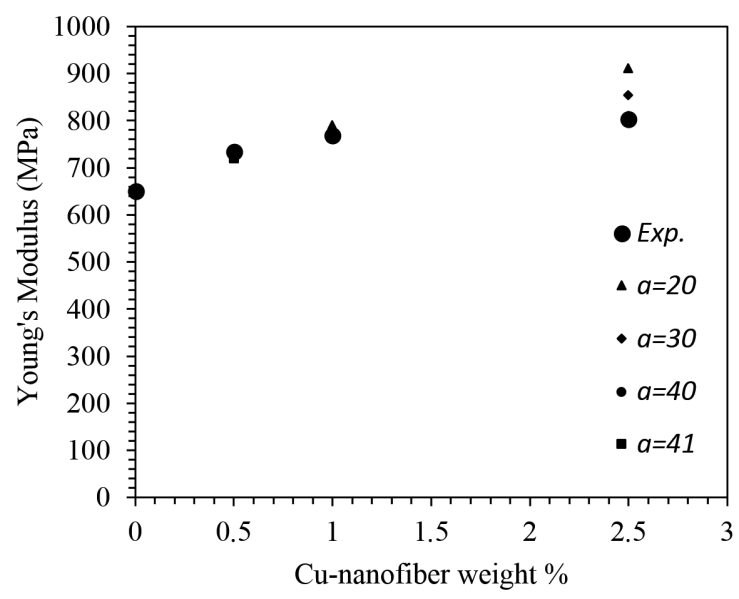

Figure 3. Effect of the aggregation-related constant (a) on Elastic modulus. 
the pristine HDPE and the maximum $\mathrm{Cu}$-nanofiber contents (2.5wt\%Cu-nanofiber). Moreover, there were no results beyond this content, and were no dramatic increase in the modulus, this confirmed the fact that the mechanical percolation threshold was not reached.

Elastic modulus increases as the $\mathrm{Cu}$-nanofiber loadings increases. In addition, this increase in elastic modulus is also accompanied by a reduction of gas permeability coefficient as the loadings of $\mathrm{Cu}$-nanofiber increased ${ }^{31}$. At the deduction of Equation 7, some assumptions were applied such as the percolation concentration of the nanofiller was not reached, and lower nanofiller permeability to oxygen coefficient in comparison with matrix permeability coefficient, which are true in gas transport process case as well. Thus, Equation 7 can be used to describe relative permeability to oxygen coefficient in the following form ${ }^{27}$

$$
\frac{P_{m}}{P_{c}}=\left[\frac{1+125 \exp (-41 \varnothing)\left(\frac{1 / 6\left(E_{f} / E_{m}\right)-1}{1 / 6\left(E_{f} / E_{m}\right)+125 \exp (-41 \varnothing)}\right) \varnothing}{1-\left(\frac{1 / 6\left(E_{f} / E_{m}\right)-1}{1 / 6\left(E_{f} / E_{m}\right)+125 \exp (-41 \varnothing)}\right) \varnothing}\right]
$$

Where $P_{M}$ and $P_{C}$ are the permeability coefficient of the polymeric matrix and of the composite material, respectively.

The experimental results show a slightly decrease in oxygen permeability up to $1 \mathrm{wt} \% \mathrm{Cu}$-nanofiber, then a significant decrease in oxygen permeability at $2.5 \mathrm{wt} \%$ $\mathrm{Cu}$-nanofiber up to $65 \%$ relative to the HDPE matrix. This makes one believe that $2.5 \mathrm{wt} \%$ filler content is beyond the permeability percolation because of expected dramatic decrease. Also, if Equations 7 and 8 are compared, they show enhancement in the composite modulus relative to the pure HDPE matrix, and this enhancement is accompanied by reduction in permeability to oxygen of the nanofilms as the $\mathrm{Cu}$-nanofiber content increases. Therefore, elastic modulus and permeability to gas coefficient are inversely proportional.

In Figure 4, the relationship between the relative permeability to oxygen coefficient $\left(\mathrm{P}_{\mathrm{m}} / \mathrm{P}_{\mathrm{c}}\right)$ and the relative modulus of the nanocomposite $\left(\mathrm{E}_{\mathrm{c}} / \mathrm{E}_{\mathrm{m}}\right)$ is presented. Because there are only two experimental points available from both studies by Grigoriadou et al. ${ }^{30}$ Bikiaris \& Triantafyllidis ${ }^{31}$ below percolation, we expect that the relationship between the relative permeability coefficients and the relative elastic moduli is linear with a slope of 0.75 . It is worthy to mention that even we have a third point in the relative permeability at $2.5 \mathrm{wt} \%$, this point was not included in Figure 4 because it is believed that this concentration is beyond the percolation. The reduction between the $1 \mathrm{wt} \%$ and $2.5 \mathrm{wt} \%$ is large (almost $65 \%$ reduction). However, the relationship in Figure 4 does not pass through the origin and as seen in Figure 4 at $\mathrm{E}_{\mathrm{c}} / \mathrm{E}_{\mathrm{m}}=1.09$ the value of $\mathrm{P}_{\mathrm{m}} / \mathrm{P}_{\mathrm{c}}=1$, which means that at small contents of $\mathrm{Cu}-$ nanofiber the value of $\mathrm{P}_{c}$ is close to the permeability to oxygen coefficient for HDPE matrix. The above mentioned circumstances make necessary to modify Equation 8 to become as follows:

$$
P_{m}=\left[0.75\left[\frac{1+125 \exp (-41 \varnothing)\left(\frac{1 / 6\left(E_{f} / E_{m}\right)-1}{1 / 6\left(E_{f} / E_{m}\right)+125 \exp (-41 \varnothing)}\right)}{1-\left(\frac{1 / 6\left(E_{f} / E_{m}\right)-1}{1 / 6\left(E_{f} / E_{m}\right)+125 \exp (-41 \varnothing)}\right) \varnothing}\right]+0.18\right] P_{c}
$$

In addition to that, the experimental Oxygen Transmission Rate (OTR) from Bikiaris \& Triantafyllidis ${ }^{31}$ study through each film was converted to permeability coefficient using the following equation

$P=O T R x l$

Where $l$ is the thickness of the film.

Figure 5 shows the comparison of the experimental permeability to oxygen coefficient from Bikiaris \& Triantafyllidis ${ }^{31}$ study and the calculated values of the permeability to oxygen coefficient from Equation 9 as a function of weight fraction of Cu-nanofibers. As shown in Figure 5, the modified model (Equation 9) correlates well for the composite samples and gives very precise permeability to oxygen coefficient up to $1 \mathrm{wt} \%$ of $\mathrm{Cu}$-nanofiber. The maximum discrepancy between the experimental and the theoretical values was up to $2 \%$.

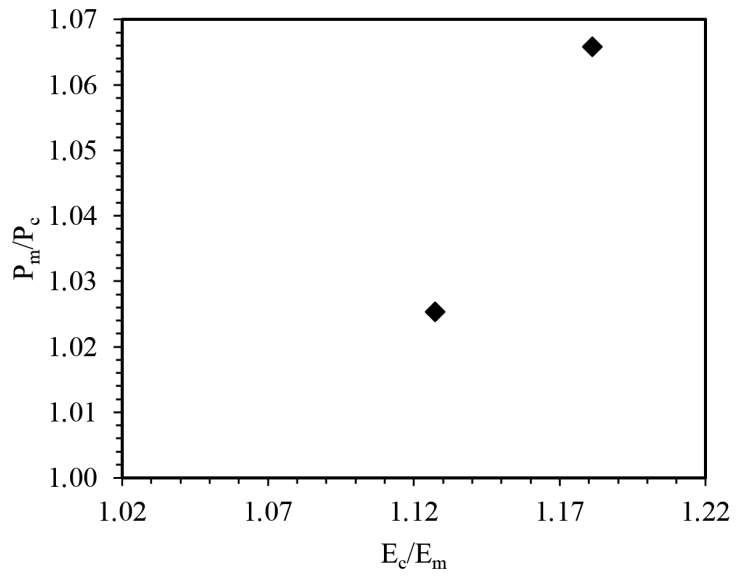

Figure 4. The comparison of relative coefficient of gas permeability and relative elastic modulus for nanocomposites of $\mathrm{HDPE} / \mathrm{Cu}$-nanofibers.

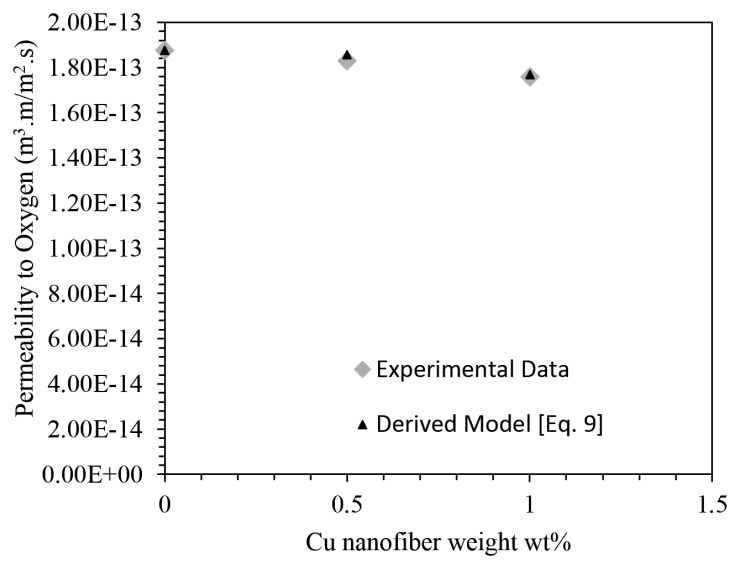

Figure 5. Experimental permeability to oxygen coefficient along with the derived model (Equation 9). 


\section{Conclusion}

$\mathrm{Cu}$-nanofibers are effective fillers for enhancing mechanical and oxygen barrier properties of HDPE. The enhancements of these properties depend on the $\mathrm{Cu}$-nanofiber content. The reduction in oxygen permeability with $\mathrm{Cu}$-nanofiber below percolation increase was due to the decrease of HDPE fraction accessible for the gas transport process. However, the reduction was not significant because HDPE has relatively low fraction of amorphousity (crystallinity is high) thus the diffusive motion of oxygen between the molecular chains of $\mathrm{PE}$ is very low. Often, oxygen transfers easily without any obstacles. Also, it was noticed that mechanical percolation is independent of permeability percolation and they happen at different filler contents. Also, this permeability model can be used to predict the permeability coefficient for composite

\section{References}

1. Peacock AJ. The chemistry of polyethylene. Journal of Macromolecular Science-Polymer Reviews. 2001; C41(4):285323. http://dx.doi.org/10.1081/MC-100107860.

2. Galli P and Vecellio G. Polyolefins: the most promising largevolume materials for the 21st century. Journal of Polymer Science Part A: Polymer Chemistry. 2004; 42(3):396-415. http://dx.doi.org/10.1002/pola.10804.

3. Vasile C and Pascu M. Practical guide to polyethylene. Shrewsbury: RAPRA Technology; 2005.

4. Halary JL, Lauprêtre F and Monnerie L. Polymer materials: macroscopic properties and molecular interpretations. Hoboken: Wiley; 2011.

5. Lu N and Oza S. Thermal stability and thermo-mechanical properties of hemp-high density polyethylene composites: effect of two different chemical modifications. Composites. Part B, Engineering. 2013; 44(1):484-490. http://dx.doi.org/10.1016/j. compositesb.2012.03.024.

6. Ayswarya EP, Francis KFV, Renju VS and Thachil ET. Rice husk ash: a valuable reinforcement for high density polyethylene. Materials \& Design. 2012; 41:1-7. http://dx.doi.org/10.1016/j. matdes.2012.04.035.

7. Souza PS, Rodrigues EF, Prêta JMC, Goulart SAS and Mulinari DR. Mechanical properties of HDPE/textile fibers composites. Procedia Engineering. 2011; 10:2040-2045. http://dx.doi. org/10.1016/j.proeng.2011.04.338.

8. Bakkal M, Bodur MS, Berkalp OB and Yilmaz S. The effect of reprocessing on the mechanical properties of the waste fabric reinforced composites. Journal of Materials Processing Technology. 2012; 212(11):2541-2548. http://dx.doi.org/10.1016/j. jmatprotec.2012.03.008.

9. Sunilkumar M, Francis T, Thachil ET and Sujith A. Low density polyethylene-chitosan composites: a study based on biodegradation. Chemical Engineering Journal. 2012; 204-206:114-124. http://dx.doi.org/10.1016/j.cej.2012.07.058.

10. Araujo JR, Mano B, Teixeira GM, Spinacé MAS and De Paoli M-A. Biomicrofibrilar composites of high density polyethylene reinforced with curauá fibers: mechanical, interfacial and morphological properties. Composites Science and Technology. 2010; 70(11):1637-1644. http://dx.doi. org/10.1016/j.compscitech.2010.06.006.

11. Liu S-P and Tu L-C. Studies on mechanical properties of dispersing intercalated silane montmorillonite in low density materials below percolation based on measuring the elastic modulus of the composite.

One important field for the produced composite materials is in pharmaceutical blisters packaging industry. With good barrier properties the shelf life of medications can be lengthen, also the cost of the blisters using this composite material can be reduced since both $\mathrm{PE}$ and $\mathrm{Cu}$-nanofibers are much cheaper than any other polymers, metal nanofibers, respectively. Also, the importance of this new material can be used in food packaging since all food packaging materials should have also good barrier properties protecting against oxygen and bacterial reaction or contamination. Food goes through biological and physical changes during storage and distribution. Also, it is very important to mention that the flexibility of the pure PE is retained while the barrier properties improved of this new material.

polyethylene matrix. International Communications in Heat and Mass Transfer. 2011; 38(7):879-886. http://dx.doi.org/10.1016/j. icheatmasstransfer.2011.04.009.

12. Zhang SA, Ke YC, Cao XY, Ma YM and Wang FS. Effect of $\mathrm{A} 12 \mathrm{O} 3$ fibers on the thermal conductivity and mechanical properties of high density polyethylene with the absence and presence of compatibilizer. Journal of Applied Polymer Science. 2012; 124(6):4874-4881.

13. AlMaadeed MA, Ouederni M and Noorunnisa Khanam P. Effect of chain structure on the properties of glass fibre/polyethylene composites. Materials \& Design. 2013; 47:725-730. http:// dx.doi.org/10.1016/j.matdes.2012.11.063.

14. Ayrilmis N. Combined effects of boron and compatibilizer on dimensional stability and mechanical properties of wood/HDPE composites. Composites. Part B, Engineering. 2013; 44(1):745749. http://dx.doi.org/10.1016/j.compositesb.2012.04.002.

15. Liao CZ, Bao SP and Tjong SC. Effect of silicon carbide nanoparticle additions on microstructure and mechanical behavior of maleic anhydride compatibilized high density polyethylene composites. Composite Interfaces. 2011; 18(2):107-120. http:// dx.doi.org/10.1163/092764411X567404.

16. Liu Y, Hu Y, Liu T, Ding JL and Zhong WH. Mechanical behavior of high density polyethylene and its carbon nanocomposites under quasi-static and dynamic compressive and tensile loadings. Polymer Testing. 2015; 41:106-116. http://dx.doi.org/10.1016/j. polymertesting.2014.11.003.

17. Kuila T, Bose S, Mishra AK, Khanra P, Kim NH and Lee JH. Effect of functionalized graphene on the physical properties of linear low density polyethylene nanocomposites. Polymer Testing. 2012; 31(1):31-38. http://dx.doi.org/10.1016/j. polymertesting.2011.09.007.

18. Urresti O, Gonzalez A, Fernandez-Berridi MJ, Iruin JJ and Irusta L. Oxygen permeability through poly(ethylene-co-vinyl acetate)/clay nanocomposites prepared by microwave irradiation. Journal of Membrane Science. 2011; 373(1-2):173-177. http:// dx.doi.org/10.1016/j.memsci.2011.03.003.

19. Yousefi N, Gudarzi MM, Zheng Q, Lin X, Shen X, Jia J, et al. Highly aligned, ultralarge-size reduced graphene oxide/ polyurethane nanocomposites: Mechanical properties and moisture permeability. Composites. Part A, Applied Science and Manufacturing. 2013; 49:42-50. http://dx.doi.org/10.1016/j. compositesa.2013.02.005.

20. Rhim J-W, Park H-M and Ha C-S. Bio-nanocomposites for food packaging applications. Progress in Polymer Science. 
2013; 38(10-11):1629-1652. http://dx.doi.org/10.1016/j. progpolymsci.2013.05.008.

21. Livi S, Sar G, Bugatti V, Espuche E and Duchet-Rumeau J. Synthesis and physical properties of new layered silicates based on ionic liquids: improvement of thermal stability, mechanical behaviour and water permeability of PBAT nanocomposites. RSC Advances. 2014; 4(50):26452-26461. http://dx.doi.org/10.1039/ c4ra02143f.

22. Song P, Yu Y, Zhang T, Fu S, Fang Z and Wu Q. Permeability, viscoelasticity, and flammability performances and their relationship to polymer nanocomposites. Industrial \& Engineering Chemistry Research. 2012; 51(21):7255-7263. http://dx.doi. org/10.1021/ie300311a.

23. Famá L, Rojo PG, Bernal C and Goyanes S. Biodegradable starch based nanocomposites with low water vapor permeability and high storage modulus. Carbohydrate Polymers. 2012; 87(3):1989-1993. http://dx.doi.org/10.1016/j.carbpol.2011.10.007.

24. Nawani P, Burger C, Rong L, Hsiao BS and Tsou AH. Structure and permeability relationships in polymer nanocomposites containing carbon black and organoclay. Polymer. 2015; 64:1928. http://dx.doi.org/10.1016/j.polymer.2015.02.041.

25. Yang F, Manitiu M, Kriegel R and Kannan RM. Structure, permeability, and rheology of supercritical CO2 dispersed polystyrene-clay nanocomposites. Polymer. 2014; 55(16):39153924. http://dx.doi.org/10.1016/j.polymer.2014.05.020.

26. Decker JJ, Meyers KP, Paul DR, Schiraldi DA, Hiltner A and Nazarenko S. Polyethylene-based nanocomposites containing organoclay: a new approach to enhance gas barrier via multilayer coextrusion and interdiffusion. Polymer. 2015; 61:42-54. http:// dx.doi.org/10.1016/j.polymer.2015.01.061.

27. Choudalakis G and Gotsis A. Recent developments in the permeability of polymer clay nanocomposites. In: Pandey JK, Reddy KR, Mohanty AK and Misra M, editors. Handbook of polymernanocomposites: processing, performance and application. Heidelberg: Springer-Verlag Berlin Heidelberg; 2014. p. 415-451.

28. Arash B, Wang Q and Varadan VK. Mechanical properties of carbon nanotube/polymer composites. Scientific Reports. 2014; 4:1-24.

29. Kalendova A, Merinska D, Gerard JF and Slouf M. Polymer/ clay nanocomposites and their gas barrier properties. Polymer Composites. 2013; 34(9):1418-1424. http://dx.doi.org/10.1002/ pc. 22541 .

30. Grigoriadou I, Paraskevopoulos KM, Karavasili M, Karagiannis G, Vasileiou A and Bikiaris D. HDPE/Cu-nanofiber nanocomposites with enhanced mechanical and UV stability properties.
Composites. Part B, Engineering. 2013; 55:407-420. http:// dx.doi.org/10.1016/j.compositesb.2013.07.002.

31. Bikiaris DN and Triantafyllidis KS. HDPE/Cu-nanofiber nanocomposites with enhanced antibacterial and oxygen barrier properties appropriate for food packaging applications. Materials Letters. 2013; 93:1-4. http://dx.doi.org/10.1016/j. matlet.2012.10.128.

32. Stauffer D and Aharony A. Introduction to percolation theory: revised. 2nd ed. New York: Taylor \& Francis; 1994.

33. Nawaz K, Khan U, Ul-Haq N, May P, O’Neill A and Coleman $\mathrm{JN}$. Observation of mechanical percolation in functionalized graphene oxide/elastomer composites. Carbon. 2012; 50(12):44894494. http://dx.doi.org/10.1016/j.carbon.2012.05.029.

34. Stankovich S, Piner RD, Nguyen ST and Ruoff RS. Synthesis and exfoliation of isocyanate-treated graphene oxide nanoplatelets. Carbon. 2006; 44(15):3342-3347. http://dx.doi.org/10.1016/j. carbon.2006.06.004.

35. Liff SM, Kumar N and McKinley GH. High-performance elastomeric nanocomposites via solvent-exchange processing. Nature Materials. 2007; 6(1):76-83. http://dx.doi.org/10.1038/ nmat1798.

36. $\mathrm{Hu} \mathrm{L}, \mathrm{Wu} \mathrm{H}$ and Cui Y. Metal nanogrids, nanowires, and nanofibers for transparent electrodes. MRS Bulletin. 2011; 36(10):760-765. http://dx.doi.org/10.1557/mrs.2011.234.

37. Cho YS and Huh YD. Synthesis of ultralong copper nanowires by reduction of copper-amine complexes. Materials Letters. 2009; 63(2):227-229. http://dx.doi.org/10.1016/j.matlet.2008.09.049.

38. Gooch J. ASTM D638. In: Gooch J, editor. Encyclopedic dictionary of polymers. New York: Springer; 2011. p. 51-51.

39. Affdl J and Kardos J. The Halpin-Tsai equations: a review. Polymer Engineering and Science. 1976; 16(5):344-352. http:// dx.doi.org/10.1002/pen.760160512.

40. Halpin JC. Effects of environmental factors on composite materials. Ohio: Air Force Materials Laboratory; 1969. Technical Report AFML-TR-67-423. DTIC Document.

41. Cox HL. The elasticity and strength of paper and other fibrous materials. British Journal of Applied Physics. 1952; 3(3):72-79. http://dx.doi.org/10.1088/0508-3443/3/3/302.

42. Montazeri A, Javadpour J, Khavandi A, Tcharkhtchi A and Mohajeri A. Mechanical properties of multi-walled carbon nanotube/epoxy composites. Materials \& Design. 2010; 31(9):4202-4208. http://dx.doi.org/10.1016/j.matdes.2010.04.018.

43. Yeh MK, Tai NH and Liu JH. Mechanical behavior of phenolic-based composites reinforced with multi-walled carbon nanotubes. Carbon. 2006; 44(1):1-9. http://dx.doi.org/10.1016/j. carbon.2005.07.005. 